Document downloaded from:

http://hdl.handle.net/10251/64166

This paper must be cited as:

Leiva-Brondo, M.; Rosello Ripolles, S.; Cebolla Cornejo, J.; Martí, R.; Macua, JI.; Lahoz, I.; González, Á.... (2015). Sugar and acid profile of processing tomato cultivars grown under conventional or organic conditions. Acta Horticulturae. 1081:181-186. http://hdl.handle.net/10251/64166.

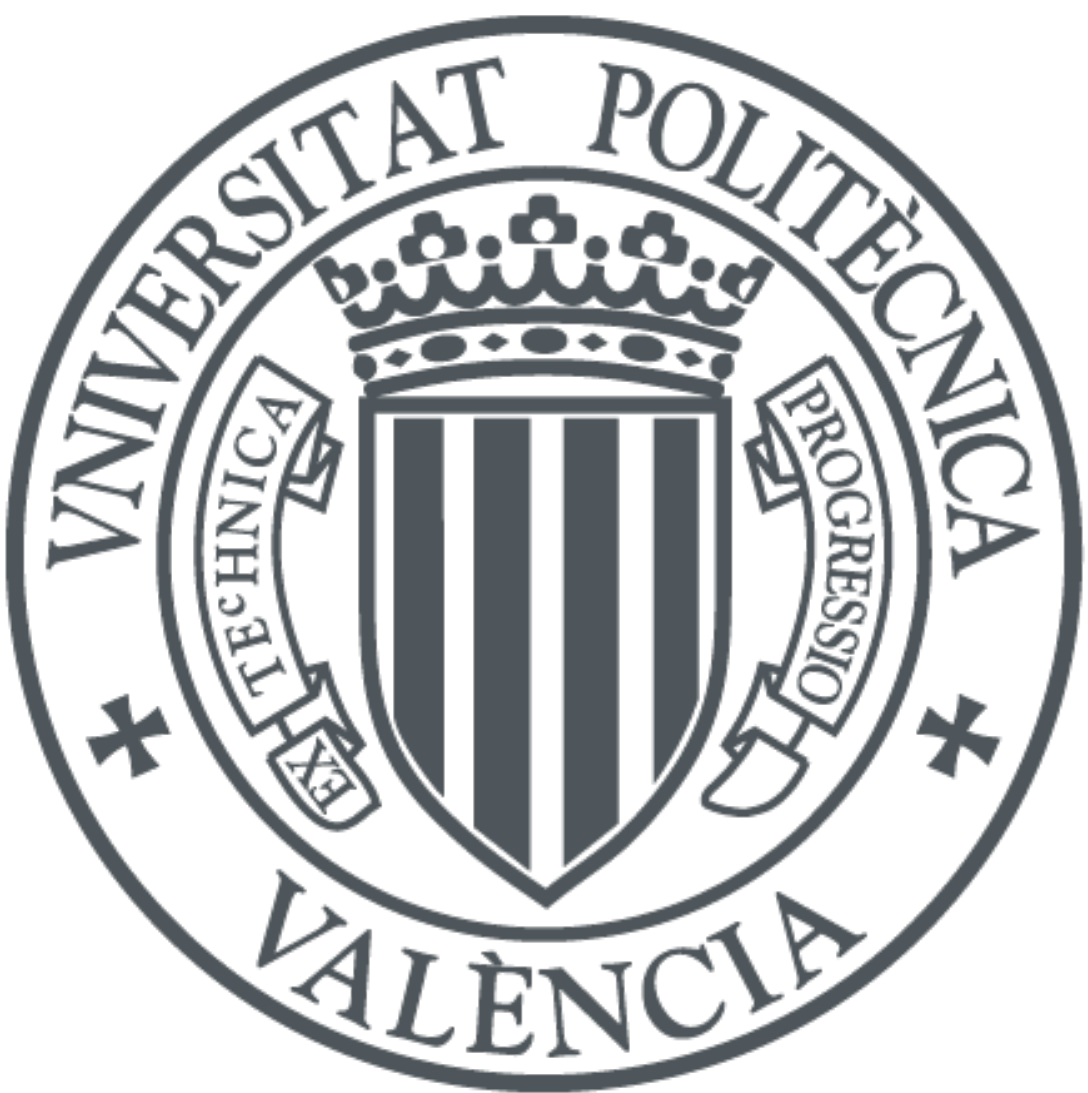

The final publication is available at

Copyright International Society for Horticultural Science (ISHS)

Additional Information 
Document downloaded from:

http://hdl.handle.net/10251/64166

This paper must be cited as:

Leiva-Brondo, M.; Raul; Juan Ignacio; Inmaculada; Carlos; Rosello Ripolles, S.; Cebolla Cornejo, J. (2015). Sugar and acid profile of processing tomato cultivars grown under conventional or organic conditions. Acta Horticulturae. 1081:181-186. http://hdl.handle.net/10251/64166.

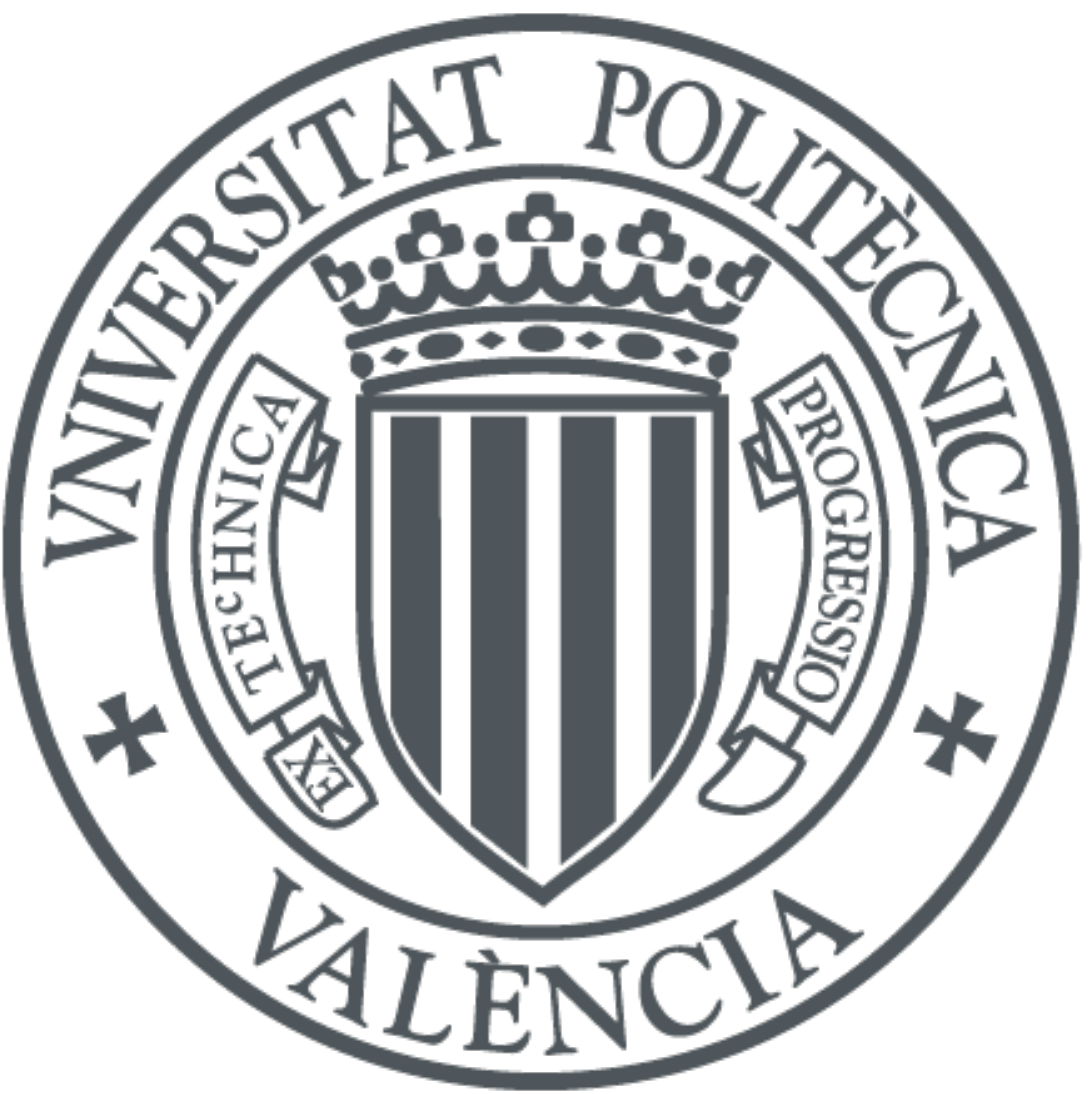

The final publication is available at

Copyright International Society for Horticultural Science (ISHS)

Additional Information 


\title{
Sugar and acid profile of processing varieties of tomato grown under conventional or organic conditions
}

\author{
Miguel Leiva-Brondo ${ }^{1}$, Raúl Martí ${ }^{2}$, Juan Ignacio Macua ${ }^{3}$, Inmaculada Lahoz ${ }^{3}$, \\ Ángel González ${ }^{4}$, Carlos Campillo ${ }^{4}$, Salvador Roselló ${ }^{2}$, Jaime Cebolla-Cornejo ${ }^{1}$ \\ ${ }^{1}$ Universitat Politècnica de València. COMAV. Cno. de Vera s/n, 46022 Valencia, Spain \\ ${ }^{2}$ Universitat Jaume I, Dept. Ciencias Agrarias y del Medio Natural Campus de RiuSec, \\ 12071 Castellón, Spain \\ ${ }^{3}$ Instituto Navarro de Tecnologías e Infraestructuras Agroalimentarias (INTIA), Avda. \\ Serapio Huici, 20-22. 31060 Villava (Navarra), Spain \\ ${ }^{4}$ Centro de Investigación. Finca La Orden-Valdesequera, Ctra. A-V, km 372, 06187 \\ Guadajira (Badajoz), Spain
}

Keywords: fructose, glucose, citric, malic, quality, Solanum lycopersicon

\begin{abstract}
The effect of conventional and organic cultivation on the sugar and acid profile of processing varieties with different lycopene accumulation has been studied in Navarra and Extremadura, the two main growing regions in Spain. High differences in the acid profile (malic vs. citric) and in the sugar accumulation of the varieties were found. In some cases, the higher values in the content of taste-related compounds coincide with previously described high lycopene contents. The cultivation system had no significant effect on malic and citric acid accumulation, but it affected sugar accumulation and the sucro equivalents (SEq) to citric and glutamic acid ratios. An average, $7.7 \%$ and $10.4 \%$ higher contents of glucose and fructose respectively were obtained with the organic cultivation system. The SEq to citric acid and SEq to glutamic acid ratios were consequently higher with this system (8.3\% and $46.3 \%$ respectively). Organic cultivation of high lycopene cultivars might be an excellent selection to combine high organoleptic and functional quality targeted to quality markets.
\end{abstract}

\section{INTRODUCTION}

There is a growing trend to obtain healthy food with the minimum impact on the environment. Consumers are also increasingly demanding food products with outstanding organoleptic quality and functional value. Organic agriculture with low input requirements might respond to these demands. In this work, conventional and organic farming systems are compared analysing the sugar and acid profiles of processing varieties of tomato in order to assess the possible effects of the growing system on organoleptic quality. Varieties differing in their lycopene accumulation were selected to analyse a possible combination of functional and organoleptic value.

\section{MATERIALS AND METHODS}

Plant material and experimental design

Eight varieties of processing tomato with high (Kalvert, AG-5 and ISI-24424), intermediate to high (CXD-277, H-9997 and H-7204) or standard lycopene contents (H-9661 and H- 
9036) were grown under conventional and organic farming systems, in two locations. The assays were performed during the 2012 campaign in the two most important areas of cultivation of processing tomato in Spain: Extremadura and Navarra. In Extremadura both conventional and organic cultivation were performed in the same area (Centro de Investigación Finca "La Orden-Valdesequera" in Badajoz) while in Navarra conventional cultivation was performed in Cadreita (Finca Experimental of INTIA) and organic cultivation was performed in a field provided by GUMENDI company in Lodosa, with similar edapho-climatic characteristics to those of Cadreita.

A complete random block experimental design with three replicates of each condition was followed. Two representative fruits were collected from 25 plants in the replicate. Fruits were pooled and homogenized obtaining a single sample, thus obtaining a biological mean of the replicate.

\section{Analysis}

The sugar and acid profile of the samples was obtained quantifying contents of malic, citric and glutamic acids and the sugars fructose, glucose and sucrose (only traces were found). The method described by Cebolla-Cornejo et al. (2012), based on capillary electrophoresis was followed. The variables sucrose equivalents (SEq), and the ratios SEq to citric acid and SEq to malic acid (Cebolla-Cornejo et al., 2011) were also calculated, considering their relation with the sensory perception by the consumer.

\section{Statistics}

The effects of location, variety and cultivation system as well as their interactions were studied with ANOVA analysis. For a more comprehensive analysis, the variety and cultivation effect on each location was also studied using MANOVA biplots. With this graphical methodology, the similarity between groups can be measured as function of its distance on the graph and the angle between variables can be interpreted as an approximation of its correlation. This analysis was performed using the free-licensed software MultBiplot from Salamanca University Prof. Vicente-Villardon (2010).

\section{RESULTS AND DISCUSSION}

Location of cultivation significantly affected acid accumulation, while it had no significant effect on sugar contents (Table 1). Consequently, it also affected SEq to citric and SEq to glutamic ratios. Extremadura growing conditions offered higher levels of malic acid and lower levels of citric and glutamic acids.

The variety factor had significant effects on all variables but in the SEq to glutamic ratio. High differences in the acid profile of the varieties analysed were found (Fig. 1). The varieties Kalvert and ISI-24424 tended to offer higher malic concentrations while the varieties H-9661 and H-7204 tended to accumulate higher levels of malic acid. Malic acid has a low impact on titratable acidity compared to citric acid, while it is sourer than citric (Debruyn et al., 1971) and its effect on $\mathrm{pH}$ is more relevant (Fulton et al., 2002). Location $\mathrm{x}$ variety interaction was detected, although it slightly affected the general trends caused by the variety effect (Fig. 1). Sucrose was not detected in any material. The absence of sucrose accumulation is a standard feature of tomatoes given that the sucrose is hidrolized during the rippening process and the concentration at the ripe stage is always below $0.1 \%$ of fresh weight (Davies y Hobson, 1981). Higher contents of glucose and fructose were detected in the varieties CXD277, H7204 and Kalvert. Again the location x variety interaction modified the sugar profile. For example, Navarra tended to increased sugar content of the variety Kalvert while higher contents in the variety CXD277 were obtained in Extremadura 
(Fig. 1). The sugar and acid profile of CXD277, with intermediate to high lycopene content and of Kalvert with high lycopene content enables the identification of materials that might offer high functional and organoleptic value.

The cultivation system had no significant effect on malic and citric acid accumulation, but it affected sugar accumulation and thus also the SEq to citric and glutamic acid ratios. Higher glutamic acid concentrations (average 25.6\%) were obtained with conventional cultivation (Fig. 2). In the case of the sugars, the organic growing system tended to offer higher contents. As an average, 7.7\% and 10.4\% higher contents of glucose and fructose were obtained with these conditions respectively. The SEq to citric acid and SEq to glutamic acid ratios were consequently higher with the organic cultivation system $(8.3 \%$ and $46.3 \%$ respectively). Again the location $\mathrm{x}$ cultivation system interaction was significant, and the increases in these ratios were higher in Extremadura than in Navarra (Fig. 2).

Considering previous works, Barrett et al., (2007) observed higher total soluble solids (moderately correlated with sugar accumulation) and titratable acidity (correlated with citric and malic acids, Davies and Hobson, 1991) in organic production in several of the farms analysed. Riahi et al. (2009) obtained similar conclusions, observing a trend towards higher titratable acidity in organic production. Total soluble solids were higher in some cv. under organic production, but in this case a strong genotype $\mathrm{x}$ cultivation system interaction was detected. Hallman (2012) observed higher total sugars in organic production, but only in one of the years analysed. Unlike the previously described studies, these authors found higher titratable acidity under conventional conditions, and higher sugars to acid ratio organic production. Our results seem to corroborate a higher effect of organic cultivation in the sugar accumulation than in the acid profile.

Higher fructose and glucose contents and higher SEq to citric and glutamic acid ratios have been associated with improved tomato taste (Baldwin et al., 1998; Bucheli et al., 1999; Cebolla-Cornejo et al., 2011). Therefore, the changes in the sugar and acid profile of taste related compounds observed in the organic farming cultivation system might result in a better organoleptic quality. Nevertheless, the genotype effect seems to be more prominent than the environment. Therefore a selection of the cultivar should be carefully addressed in productions targeted to quality markets.

\section{CONCLUSIONS}

The different sugar and acid profile of tomato processing varieties with different levels of lycopene accumulation enables the selection of genotypes with both high taste and functional characteristics. Organic farming tends to increase sugar content while maintaining acid accumulation. The level of this increase may depend on the location of cultivation. Organic cultivation of high lycopene cultivars might be an excellent selection to combine high organoleptic and functional quality targeted to quality markets.

\section{ACKNOWLEDGEMENTS}

This research was funded by INIA (RTA2011-00062), FEDER and Gobierno de Extremadura (GRU 10130).

\section{Literature cited}


Baldwin, E.A., Scott, J.W., Einstein, M.A., Malundo, T.M.M., Carr, B.T., Shewfelt, R.L. and Tandon, K.S. 1998. Relationship between sensory and instrumental analysis for tomato flavor. J. Am. Soc. Hortic. Sci. 123:906-915.

Barrett, D.M., Weakley, C., Diaz, J.V., and Watnik, M. 2007. Qualitative and nutritional differences in processing tomatoes grown under commercial organic and conventional production systems. J. Food Sci. 72:C441-C451.

Bucheli, P., Voirol, E., Torre, R. R., Lopez, J., Rytz, A., Tanksley, S. D., Petiard, V. and de la Torre, R. 1999. Definition of nonvolatile markers for flavor of tomato (Lycopersicon esculentum Mill.) as tools in selection and breeding. J. Agric. Food Chem. 47:659-664.

Cebolla-Cornejo, J., Roselló, S., Valcárcel, M., Serrano, E., Beltrán, J. and Nuez, F. 2011. Evaluation of genotype and environment effects on taste and aroma flavor components of Spanish fresh tomato varieties. J. Agric. Food Chem. 59:2440-2450.

Cebolla-Cornejo, J., Valcárcel, M., Herrero-Martínez, J. M., Roselló, S. and Nuez, F. 2012. High efficiency joint CZE determination of sugars and acids in vegetables and fruits. Electrophoresis 33:2416-2423.

Davies, J.N. and Hobson, G.E. 1981. The constituents of tomato fruit - the influence of environment, nutrition, and genotype. CRC Critical Rev. Food Sci. Nutr. 15:205-280.

Debruyn, J.W., Garretse.F. and Kooistra, E., 1971. Variation in taste and chemical composition of tomato (Lycopersicon esculentum Mill.). Euphytica 20:214-227.

Fulton, T.M., Bucheli, P., Voirol, E., Lopez, J., Petiard, V. and Tanksley, S.D. 2002. Quantitative trait loci (QTL) affecting sugars, organic acids and other biochemical properties possibly contributing to flavor, identified in four advanced backcross populations of tomato. Euphytica, 127:163-177.

Hallmann, E. 2012. The influence of organic and conventional cultivation systems on the nutritional value and content of bioactive compounds in selected tomato types. J. Sci.Food Agric. 92:2840-2848.

Lahoz, I., Campillo, C., González, J. A., Cebolla, J., Roselló, S., and Macua, J. I. 2013. Efecto del manejo ecológico y convencional sobre la producción y calidad en el tomate de industria.VII Actas del Congreso Ibérico de Agroingeniería y Ciencias Hortícolas. Madrid, 28-29 agosto 2013:

Riahi, A., Hdider, C., Sanaa, M., Tarchoun, N., Ben Kheder, M. and Guezal, I. 2009. Effect of conventional and organic production systems on the yield and quality of field tomato cultivars grown in Tunisia. J. Sci. Food Agric. 89:2275-2282.

Vicente-Villardon, J.L. (April 2012) MULTBIPLOT: A package for Multivariate Analysis using Biplots. http://biplot.dep.usal.es/classicalbiplot/ 


\section{Tables}

Table 1. Influence of the factors analysed on taste-related variables (ANOVA p-values).

\begin{tabular}{ccccccccc} 
Factor & $\begin{array}{c}\text { Malic } \\
\text { acid }\end{array}$ & $\begin{array}{c}\text { Glutamic } \\
\text { acid } \\
\text { (GLUT) }\end{array}$ & $\begin{array}{c}\text { Citric } \\
\text { acid } \\
(\mathrm{CIT})\end{array}$ & Fructose & Glucose & $\begin{array}{c}\text { Sucrose } \\
\text { equivalents } \\
\text { (SEQ) }\end{array}$ & SEQ/CIT & SEQ/GLUT \\
\hline $\begin{array}{c}\text { Location } \\
(\mathrm{L})\end{array}$ & $<10^{-4}$ & $<10^{-4}$ & $<10^{-4}$ & 0.060 & 0.092 & 0.067 & 0.005 & $10^{-4}$ \\
$\begin{array}{c}\text { Variety (V) } \\
\text { Cultivation }\end{array}$ & $10^{-4}$ & 0.022 & $<10^{-4}$ & $<10^{-4}$ & $<10^{-4}$ & $<10^{-4}$ & $<10^{-4}$ & 0.067 \\
system (C) & 0.110 & $<10^{-4}$ & 0.167 & 0.003 & 0.010 & 0.005 & $<10^{-4}$ & $<10^{-4}$ \\
Lx V & $<10^{-4}$ & 0.054 & $10^{-4}$ & $10^{-4}$ & 0.018 & 0.007 & 0.0102 & 0.747 \\
Lx C & 0.051 & 0.794 & 0.723 & 0.129 & 0.002 & 0.007 & 0.005 & 0.007 \\
V X C & 0.357 & 0.785 & 0.110 & $10^{-4}$ & 0.081 & 0.029 & 0.054 & 0.946 \\
LX V X C & 0.256 & 0.816 & 0.043 & 0.003 & 0.071 & 0.025 & 0.987 & 0.981 \\
\hline
\end{tabular}




\section{Figures}
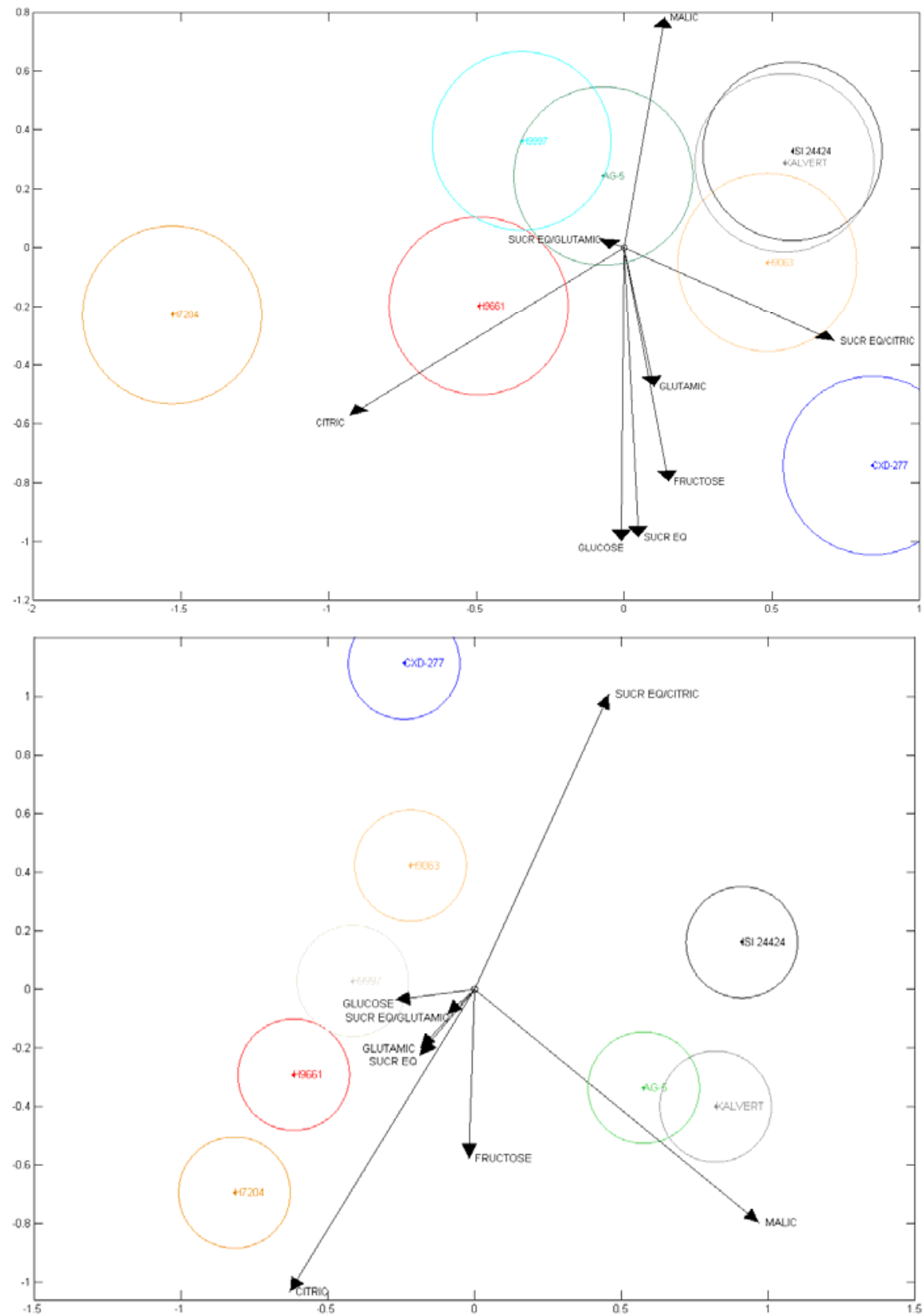

Fig. 1. MANOVA biplot analysis of the variety effect on taste-related variables in Extremadura (top) and Navarra (bottom). 

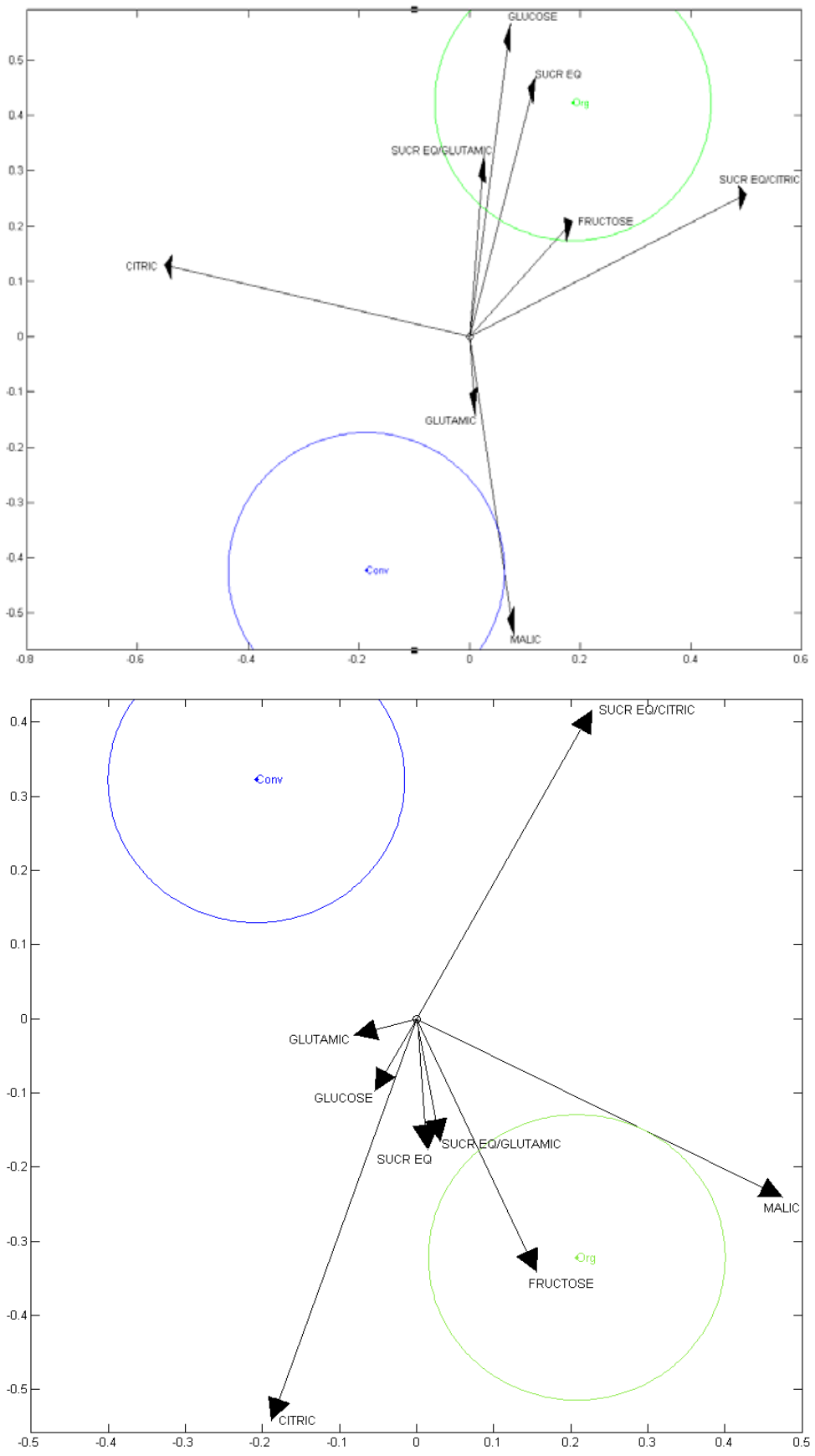

Fig. 2. MANOVA biplot analysis of the effect of cultivation system (Conv: Conventional; Org: Organic farming) on taste-related variables in Extremadura (top) and Navarra (bottom). 